DOSSIÊ TEMÁTICO: Vitalidade do sujeito e poder de formação: narrativas autobiográficas em diálogo

\title{
INVESTIGAÇÃO BIOGRÁFICA E ANÁLISE COM SOFTWARE: COOPERAÇÃO, EMPODERAMENTO, (DES)ENVOLVIMENTO
}

\author{
BIOGRAPHICAL RESEARCH AND SOFTWARE ANALISIS: COOPERATION, POWER \\ AND PEOPLE DEVELOPMENT
}

\author{
INVESTIGACIÓN BIOGRÁFICA Y SOFTWARE DE ANÁLISIS: LA COOPERACIÓN, \\ EL PODER Y EL DESARROLLO DEL SUJETO
}

Conceição Leal da Costa

Universidade de Évora - Portugal

João Paulo Oliveira

Instituto Federal de Rio Grande do Norte - Brasil Universidade de Évora - Portugal

\section{Isabel Cavas \\ Universidade de Évora - Portugal}

Resumo: Neste artigo discutimos algumas questões em torno da investigação biográfica, baseando-nos na que temos desenvolvido, quer na formação de professores, quer com jovens estudantes ou com adultos em situação de vulnerabilidade. Argumentamos, num primeiro momento, sobre a centralidade, atualidade e importância de narrativas e histórias de vida no campo educacional. Assumem-se como fundamentais, numa investigação contemporânea, porque: epistemologicamente ancoradas, ao permitirem construir conhecimento centrado em experiência humana compartilhada; teoricamente sustentadas, ao contemplar o espaço/tempo do vivido e uma compreensão humanizada na produção de conhecimento; metodologicamente implicadas, ao serem coerentes e hábeis na promoção da mudança, com socialização do poder entre os diferentes participantes, aqui entendidos sujeito e investigador. Em seguida, discorremos sobre a relevância de uma investigação biograficamente orientada no desenvolvimento dos sujeitos, incluindo os investigadores. Para tanto, explicitaremos os entendimentos sobre a cooperação, as necessárias coerências entre o objeto de estudo, a metodologia e inerentes questões éticas. Defendemos, igualmente, uma utilização adequada de software de análise. Ilustra-se, então, um processo de análise de narrativas, deixando sobressair relações emergentes e cooperadas construções de sentidos, assim como destacamos avanços teórico-metodológicos coadjuvados pelo NVIVO. Compreendendo que percursos investigativos biograficamente orientados podem ser, em si mesmos, promotores de mudanças, sustentadas e sustentáveis, de quem participa na investigação e dos quotidianos que habitamos. Defende-se, enfim, que os processos de produção das narrativas e as opções de análise podem constituir-se em propostas e avanços teórico-metodológicos, se o rigor da interpretação e a profundidade da reflexão entre sujeitos forem acautelados e adequadamente socializados.

Palavras-chave: Investigação biográfica; Cooperação; Desenvolvimento. 


\begin{abstract}
In this article, we discuss some issues surrounding biographical research, based on what we have developed, either in teacher training, or with young students or adults in vulnerable situations. We argued, at first, about the centrality, timeliness and importance of narratives and life stories in the educational field. Assumed to be fundamental, in a contemporary investigation, because: epistemologically anchored, to allow knowledge centered on shared human experience; theoretically supported, when contemplating the space / time of the lived and a humanized understanding in the production of knowledge; methodologically involved, as they are coherent and change is promoted, with socialization of power between different participants, they are presented and investigated here. Then, we discuss the relevance of this investigation for the development of individuals, as well as for researchers. Explaning how the ventures on cooperation, such as restrictions of coherence between the object of study, the methodology and the inherent ethical issues. We also advocate an adequate use of the analysis software. It then illustrates a process of analyzing narratives, highlighting emerging and cooperative relations of meanings, as well as highlighting theoretical and methodological advances supported by NVIVO. Understanding the biographically oriented research paths can be, in themselves, promoters of changes, sustained and sustainable, and the societies that inhabit, it is argued, that contexts of production of narratives and analysis options are not indifferent. The ethical classification and the complexity of telling and socializing stories, submerging ourselves implicitly, going to hidden times and spaces, often silent, but reproduced to record memories.
\end{abstract}

Keywords: Biographical research; cooperation; development.

Resumen: Este artículo discute las cuestiones sobre la investigación biográfica, a partir del trabajo desarrollado en los últimos años, tanto en la formación de docentes y de estudiantes, como en proyectos con adultos vulnerables. Primero discutimos sobre la centralidad, actualidad e importancia de las narrativas en el campo educativo, suponiendo que son fundamentales en una investigación contemporánea al estar: ancladas epistemológicamente, construyendo conocimiento centrado en la experiencia humana compartida; basadas teóricamente, contemplando el espacio/tiempo de lo vivido y la comprensión que permite humanizar la producción de conocimiento; y estando relacionadas metodológicamente, en su capacidad de promover cambio a través de la socialización del poder entre los diferentes individuos. Discutimos la relevancia de esta investigación para la formación y el desarrollo de los sujetos y de los investigadores. Para ello, haremos explícitos la comprensión sobre el uso del software de análisis y los problemas éticos inherentes, reiterando que NVIVO puede facilitar avances teóricos y metodológicos en la investigación. Ilustramos un proceso de análisis de narrativas, destacando relaciones, así como construcciones de significados emergentes y cooperativos. Entendemos que estos caminos de investigación orientados biográficamente pueden ser promotores de cambio, sostenidos y sostenibles, de sí mismos y de las sociedades que habitamos. Finalmente, defendemos la importancia de los contextos de producción de narrativas y de las opciones de análisis, ya que nos permiten contar y socializar historias, sumergirnos, ir a tiempos y espacios ocultos y casi olvidados, pero que se han vuelto significativos y, por ende, inscritos en la memoria.

Palabras clave: investigación biográfica; cooperación; desarrollo.

\title{
Introdução
}

No presente artigo, como investigadores na área da educação, partilhamos uma reflexão e visão sobre a forma como poderemos orientar o nosso pensamento, no que respeita à investigação biográfica. Para tanto, apresentamos e discutimos a análise e interpretação do 
conteúdo de duas entrevistas narrativas realizadas com estudantes participantes de um Programa de Apoio Institucional à Extensão (PAIE).

Numa primeira instância, defendemos e salientamos a relevância, pertinência, atualidade e necessidade, que no nosso entender, deve ser dada à utilização de uma abordagem biográfica num estudo investigativo. Falar e pensar na palavra biografia é direcionar a atenção para alguém em concreto e com isso torná-la sujeito de investigação. É conhecer e compreender uma trajetória de vida singular, repleta de acontecimentos, vivências e memórias que identidicam cada um como ser no mundo. É afirmar o humano, os tempos e espaços que permitiram escrever a sua história. O contar essas experiências possibilita construir conhecimento, tanto para o investigador que está a conhecer o mundo daquele participante, como também para o sujeito que pensando nos seus antecedentes revive o seu passado, pensa o presente e tenta construir o futuro. É por isso que o escutar, o ouvir, o estar atento ao que o outro diz e pensa é um importante meio de socialização, de partilha e sobretudo de aprendizagem.

Neste artigo que desenvolvemos a três mãos, no sentido de evidenciarmos uma experiência concreta e recente, daremos destaque à tese de doutoramento do segundo autor, apresentando duas narrativas concretizadas com dois sujeitos da sua investigação. Neste tipo de investigação e tal como aconteceu neste caso, é de extrema importância ter em atenção as questões morais e éticas, no sentido de se chegarem a acordos e consensos sobre o que se pretende recolher e posteriormente divulgar. Neste sentido, o tipo de tratamento da informação recolhida é muito importante, sendo por isso necessário que os investigadores utilizem o método que para si seja o mais adequado para a análise da informação. Neste caso concreto, defendemos a utilização do software NVIVO como instrumento facilitador e eficaz para tratar as narrativas recolhidas.

Torna-se assim essencial estabelecer um paralelismo entre o processo de conhecimento e produção das narrativas e as opções de análise existentes e viáveis para a construção de conhecimento e aprendizagens significativas, pois só assim chegados ao final de uma investigação podemos dizer que crescemos, aprendemos, pensamos, mudamos e construímos novo pensamento científico e algo novo em nós próprios. Desta forma, a ênfase de uma investigação deverá ser dada aos processos e ao que é desenvolvido no durante e não tanto aos produtos.

\section{Enquadramento conceptual}


Abordar a questão das narrativas e das histórias de vida no campo educacional é um tema cada vez mais atual e de grande interesse na investigação científica pelo alcance, conhecimentos e aprendizagens que dele podemos retirar. Tendo presente o pensamento de Afonso (2014), este tipo de abordagem tem vindo ao longo do tempo a afirmar-se pela importância e consideração atribuída aos sujeitos da investigação, no que se refere à sua singularidade e à sua trajetória de vida, centrando-se por isso "no estudo das vivências e experiências individuais” (p. 81). É dada relevância à pessoa, ao que ela representa na sociedade, ao que pensa, ao que faz, aos valores e princípios que segue, aos significados que atribui às situações e acontecimentos, aos sentimentos e comportamentos que tem no seu diaa-dia e à sua ação diária, pois não existe ninguém no mundo igual a si, cada um é uma "pessoa concreta e completa na globalidade da sua circunstância" (p. 81). Neste sentido, falar em estudos biográficos é passar de um tipo de investigação mais estandardizada, tradicional e rigorosa para uma investigação onde os sujeitos e a sua voz são a chave para o desenvolvimento de um estudo (Pineau, 2006; Ferrarotti, 2013; Vilelas, 2017). Como tal e considerando DeloryMomberger (2012), a abordagem biográfica foca-se no estudo do individuo na sua individualidade e sociabilidade, tentando compreender quem ele é e como se formou assim, atendendo-se aos seus antecedentes, ao momento presente e a projeções futuras na interação com os outros.

O objeto da pesquisa biográfica é explorar os processos de gênese e de devir dos indivíduos no seio do espaço social, de mostrar como eles dão forma a suas experiências, como fazem significar as situações e os acontecimentos de sua existência. (DELORY-MOMBERGER, 2012, p. $524)$.

Neste seguimento, poderemos referir que cada indivíduo tem uma identidade pessoal, que é sua devido à pessoa que é, às aprendizagens adquiridas, aos contextos compartilhados e às relações estabelecidas. Apesar destas evidências serem individuais elas não se constroem e adquirem no vazio, no isolamento, ou seja, a pessoa existe com e para os outros. Os sujeitos não são seres apáticos que vivem para si próprios. Possuem também uma identidade social, sendo, por isso, agentes e atores nos contextos da sua vida. Para se desenvolverem precisam dos outros, de se expressar e partilhar as suas alegrias e dificuldades, as vitórias e os desânimos. São sujeitos sociais, agentes de ações permanentes. Desta forma, fazemos referência a Dubar 
(2005) que evidencia que a identidade é "o resultado a um só tempo estável e provisório, individual e coletivo, subjetivo e objetivo, biográfico e estrutural, dos diversos processos de socialização que, conjuntamente, constroem os indivíduos e definem as instituições” (p. 136).

Delory-Momberger (2012) referindo-se a Paul Ricoeur menciona que o relato e portanto, o que se conta nos permite conhecer e compreender a vida, os acontecimentos e as situações pelas quais os sujeitos passaram ao longo da sua trajetória, onde os tempos, espaços e lugares se foram tornando mais ou menos significativos para a construção da sua identidade. Por tal, cada individuo expõe aquilo que experiencia por meio da linguagem, da comunicação, de um diálogo aberto. Quem narra está a contar um conjunto de vivências por si vividas que refletem o seu olhar e expressam a forma como as viveu e sentiu. É a sua perspectiva porque foi ele que as experienciou daquela maneira, e por isso quem ouve não pode questionar a veracidade dessas reflexões, porque pertencem aos sujeitos na sua individualidade. Assim, "o que o relato enreda é o mundo da intencionalidade, que é próprio do agir humano e nunca redutível a uma pura causalidade antecedente" (p. 530).

Neste sentido, as abordagens biográficas apresentam um importante papel na (re)construção identitária e na compreensão daquilo que cada um é, percebendo os sujeitos que ao narrarem os momentos e acontecimentos das suas vidas estão a ter uma noção de si próprios, a (re)construir conhecimento e a potenciarem o seu desenvolvimento (Day, 2001; Sarmento, 2002; Passeggi, 2011; Costa \& Nunes, 2016). Por tal, para Sarmento (2002) ao tomar as histórias de vida como metodologia de investigação, "os investigadores tentam introduzir-se no mundo conceptual dos sujeitos, com a finalidade de compreenderem os significados que estes atribuem às suas vidas e como constroem esses mesmos significados" (p. 260). A história de vida que se conta está carregada de subjectividade, de singularidade, de uma sequência espáciotemporal própria de cada um, de experiências e lembranças com mais ou menos detalhes, conforme a relevância que lhes é atribuída, traduzindo-se numa (re)construção permanente da identidade de cada individuo (Denzin e Lincoln, 2005; Josso, 2007) e por isso Passeggi (2011) refere que "ao narrar sua própria história, a pessoa procura dar sentido às suas experiências e, nesse percurso, constrói outra representação de si: reinventa-se" (p. 147).

Ao pensar e contar o vivido, cada um encontra-se num momento de formação, aprendizagem e conhecimento. Existem lembranças, questionamentos e interpretações que conduzem cada um a refletir sobre a sua existência e sobre a sua forma de atuação ao longo da vida. Este pensar sobre as ações e com isso tentar fazer diferente é essencial para mudar paradigmas, repensar os processos educativos, olhar para os professores como foco dos estudos realizados em educação, e principalmente para dar o sentido e valor ao facto das histórias de 
vida se centrarem na compreensão e conhecimento das pessoas, das suas vidas, das suas aprendizagens, do seu desenvolvimento (Goodson, 2008; Sarmento, T., 2017; Ubaque e Castañeda-Peña, 2017). Por tal, Josso (2007) considera que "as narrações centradas na formação ao longo da vida revelam formas e sentidos múltiplos de existencialidade singularplural, criativa e inventiva do pensar, do agir e do viver junto" (p. 413), bem como Vieira (2007) que menciona que "formar é transformar, ou, antes, formar é levar a querer (trans)formar-se" (p. 10).

Tendo em consideração Josso (2007), as histórias de vida são "histórias centradas na formação" (p. 414), uma vez que a partir delas os indivíduos são levados a refletir e a expandir o seu pensamento critico sobre a realidade, questionando-a e ao mesmo tempo mudando-a com um novo olhar, novas estratégias, maior abertura e com novas possibilidades de mudança, construindo um caminho novo na forma de pensar a educação e o humano. Assim sendo, as narrativas surgem cada vez mais associadas à educação, uma vez que ao reflectir sobre a ação, as dinâmicas e as práticas diárias torna-se possível melhorar, (re)construir algo novo e definir novas metas e objetivos para o desenvolvimento e o repensar da educação.

\section{Entrevistas narrativas em um estudo de caso: compreendendo o desenvolvimento dos sujeitos}

Um caso não é visto da mesma forma por todos, ou seja, ele pode apresentar diferentes perspectivas se estudado/observado por outras pessoas que procurem descobrir e retratar realidades múltiplas (Stake, 2012). Assim, as entrevistas tornam-se uma fonte fundamental de evidência que podem contribuir com a compreensão da perspectiva adotada pelo pesquisador diante de um caso estudado (Yin, 2015). Nesse sentido, a técnica de recolha/produção de dados por meio de entrevistas, em um estudo de caso, vem para corroborar com as fontes de evidências das observações e análise documental. Para Szymanski (2011), as entrevistas são momentos de interação humana que permitem captar aspectos relacionados a percepções, expetativas, preconceitos e interpretações. Desse modo, as entrevistas podem dizer-nos muito sobre os entrevistados, pois as suas falas podem mostrar o que o pesquisador não conseguiu ver por meio da técnica de observação (Stake, 2012).

A observação é um momento de imersão do pesquisador num contexto naturalista do qual ele não exerce nenhum controle, podendo fazer apontamentos de situações que podem ser esclarecidas ou confirmadas depois. As entrevistas, ao contrário das observações, seguem uma estrutura pensada pelo pesquisador (Stake, 2012) e, portanto, permitem que o investigador 
possa focar-se em aspectos comportamentais (Yin, 2015) que não foram compreendidos pelas observações e que podem ser relevantes para o estudo de caso.

Neste estudo, a técnica de entrevista tornou-se imprescindível para, além de compor uma necessária dimensão da triangulação de dados, compreender, por meio de relatos verbais, eventos e/ou comportamentos que foram desencadeados em função da participação dos estudantes extensionistas no Programa de Apoio Institucional à Extensão (PAIE). Como a entrevista é um momento de conversa entre o pesquisador e o entrevistado, é importante que o diálogo entre ambos seja fluido e o mais natural possível, mas o pesquisador precisa ter a destreza para não perder a consistência científica da linha de investigação (Yin, 2015). Assim, em função da relação de cada participante da pesquisa com o PAIE, realizamos dois tipos de entrevista: uma de natureza semiestruturada e outra de natureza narrativa. Antes de descrevermos a diferença entre ambas e justificarmos as nossas escolhas, precisamos distinguir a entrevista estruturada e a entrevista não-estruturada. Segundo Fontana e Frey (2005) "in structured interviewing, the interviewer asks all respondents the same series of preestablished questions with a limited set of response categories" (pp. 701-702) e as "unstructured interviewing can provide greater breadth than do the other types given its qualitative nature" (p. 705).

Dessa forma, a opção pela entrevista semiestruturada visou manter o equilíbrio entre a fluidez da conversa e o rigor da investigação qualitativa, uma vez que o guião trazia questões que possibilitava relatos e respostas reflexivas, além de permitir que o pesquisador pudesse fazer outras questões não previstas em função das respostas dos participantes.

Os guiões deste tipo de entrevista continham questões diferentes, mas ambos apresentavam a mesma estrutura, divididos em três eixos, conforme Yin (2016): Eixo 1: Apresentação do estudo, identificação e histórico pessoal (acadêmico/profissional) do entrevistado; Eixo 2: Reconstrução da experiência dos entrevistados (gestores) sobre os temas que se relacionam com o estudo de caso; Eixo 3: reflexões sobre o significado da experiência que o PAIE proporcionou aos envolvidos no processo (gestores, coordenadores e estudantes extensionistas). Esse tipo de entrevista foi realizado com dois gestores e um coordenador de projeto de extensão do Programa de Apoio Institucional à Extensão (PAIE).

Para Stake (2012) cada entrevistado tem experiências únicas e histórias especiais para contar que devem ser estimuladas pelo entrevistador. Para isso, faz-se necessário o uso de guiões que sejam adequados ao nível de participação do entrevistado no evento estudado, ou seja, os guiões precisam abordar questões relacionadas diretamente às vivências do entrevistado em contextos específicos. Segundo Muylaert et al. (2014), a entrevista narrativa “[...] visa 
encorajar e estimular o sujeito entrevistado (informante) a contar algo sobre algum acontecimento importante de sua vida e do contexto social" (p. 194). Corroborando essa perspectiva, Flick (2005) reforça que as narrativas são uma opção às entrevistas semiestruturadas e permitem ao investigador uma aproximação mais aprofundada das experiências particulares dos informantes. Jovchelovitch e Bauer (2002) reforçam que a necessidade de contar histórias faz parte da natureza humana e, por meio da narrativa, as pessoas têm a oportunidade de se recordar do que aconteceu e encontrar explicações sobre determinados acontecimentos.

Dessa forma, a entrevista narrativa mostrou-se adequada aos estudantes extensionistas, pois possibilitou que eles, como participantes centrais do PAIE, pudessem narrar em detalhes as experiências que viveram durante a execução do Programa de Apoio Institucional à Extensão (PAIE) no ano de 2017 (maio a dezembro). As narrativas são consideradas uma intepretação do contexto que o participante vivenciou e construiu ao longo de um período, expressando uma reflexão sobre as experiências proporcionadas unicamente em função da participação no PAIE.

A realização das entrevistas narrativas teve como instrumento de recolha/produção um guião de entrevista narrativa que objetivou compreender como a participação no PAIE contribuiu com a formação dos estudantes extensionistas do Ensino Médio Integrado, considerando as seguintes dimensões: trajetória e experiências de vida; visão sobre a formação no EMI; contributos dos componentes curriculares para a formação humana integral; o projeto de extensão na formação do aluno; dinâmica do projeto e como ele se desenvolveu ao longo dos sete meses; aprendizagens significantes (momentos e vivências e/ou relações estabelecidas e proporcionadas); relação com os membros da comunidade externa.

Durante a realização das entrevistas narrativas foram disponibilizadas sobre a mesa algumas fotografias relacionadas com o projeto de que o estudante extensionista participou. As fotografias constavam no relatório final dos projetos, fornecidos pelos coordenadores, e tiveram como objetivo ajudá-los a lembrar os detalhes da sua experiência como estudante extensionista do Programa de Apoio Institucional à Extensão (PAIE). Ao longo da narrativa procuramos interromper o mínimo possível, não emitir qualquer tipo de opinião e procuramos sempre manifestar interesse pela conversa. Apesar de utilizar guiões, tentamos conduzir o diálogo em tom de descontração e o mais informal possível, para que o/a participante ficasse à vontade durante a narrativa.

O guião das entrevistas narrativas também estava dividido em três eixos (Yin, 2016), conforme descrito anteriormente, quando apresentamos a discussão sobre a entrevista semiestruturada. O convite para a realização das entrevistas foi feito a duas estudantes, uma de 
cada projeto de extensão. Em função das diferenças e peculiaridades dos projetos, precisamos considerar alguns fatores antes de procedermos ao convite.

No caso do projeto 1, as atividades eram realizadas em grupo e, por isso, optamos por convidar a estudante que participou em todas as ações realizadas com os participantes da comunidade externa, ou seja, que não esteve ausente em nenhum momento. No caso do projeto 2, em que as aulas de informática eram ministradas individualmente, convidamos a estudante que compreendemos ter apresentado a maior coerência e desenvoltura na interação com os participantes da comunidade.

As entrevistas realizadas foram gravadas com o consentimento das participantes. Em seguida foram transcritas com o auxílio do software Express Scribe (Versão 6.10 - Licença básica gratuita), seguindo algumas regras de transcrição elaboradas pelo pesquisador. A criação de regras de transcrição visou dar uniformidade ao processo e instruir o colaborador externo, pois em virtude da quantidade de entrevistas foi necessário recorrer à ajuda de uma outra pessoa para realizar a transcrição de algumas entrevistas. Todas as transcrições realizadas pelo colaborador externo foram revistas e comparadas com o áudio original, a fim de conferirmos a integralidade das falas.

Após a transcrição e conferência das falas, o conteúdo das entrevistas foi enviado às duas estudantes entrevistadas por $e$-mail, em arquivo de edição de texto, para que elas pudessem validar o seu próprio discurso, ou seja, realizassem a conferência do que disseram, garantindo assim a privacidade da informação, conforme pontuam Gray (2012) e Bogdan e Biklen (1994). Pedimos que lessem atentamente e estivessem à vontade para acrescentar ou retirar algum aspecto que elas entendessem que precisavam ser modificados ou excluídos. Além disso, pedimos-lhes que informassem, dentro do texto, os pontos exatos de alterações com o seguinte código: [trecho excluído a pedido do/a entrevistado/a] ou [trecho acrescentado a pedido do/a entrevistado/a]. Após esse processo, o conteúdo das entrevistas estava pronto para ser utilizado como fonte de informação na compreensão do estudo.

A recolha/produção de dados por meio da técnica de entrevistas permitiu-nos criar um conjunto de dados que trouxeram visões, pensamentos e perspectivas que contribuíram para compreender os processos formativos desenvolvidos pelas estudantes extensionistas, além de ter possibilitando um olhar interno dos pesquisadores acerca da constituição da sua identidade profissional. Assim, este artigo concentra-se na discussão dos resultados das duas entrevistas narrativas realizadas com as estudantes extensionistas escolhidas, conforme critérios descritos anteriormente. 
Análise de narrativas: construção de sentidos com recurso ao NVivo

A análise de conteúdo das entrevistas foi realizada com o suporte do software NVivo 12. Contudo, antes de fazer a análise no software, procedemos à leitura flutuante dos textos com o objetivo de compreender, previamente, os sentidos expressos. Durante esse processo, codificamos o conteúdo em unidades de registro, utilizando o software de edição de texto Word para facilitar a localização dos sentidos no texto aquando da manipulação no software NVivo. Essa codificação, feita em função da leitura flutuante, teve como objetivo auxiliar o reconhecimento de categorias emergentes, uma vez que as entrevistas conferiram liberdade aos entrevistados para discorrer abertamente sobre os temas abordados.

No caso das entrevistas narrativas com as estudantes, essa técnica que utilizamos foi particularmente importante, pois permitiu-nos perceber com acurácia as categorias. Após esse procedimento, passamos à análise com o auxílio do software NVivo. No primeiro momento, criamos, em função da leitura flutuante, o sistema de categorias para o conteúdo das duas entrevistas narrativas. Em seguida, com uma leitura em profundidade, organizamos o texto em categorias, de acordo com as unidades de registo criadas. No final do processo, o software gerou dois documentos que foram utilizados para a interpretação. As entrevistas semiestruturadas passaram pelo mesmo processo das narrativas, contudo, a criação do sistema de categorias foi facilitada, pois em função do tipo de instrumento de produção de dados, algumas categorias estavam pré-definidas e as demais foram inseridas em função da leitura flutuante realizada antes da análise no software NVivo.

A interpretação do conteúdo foi realizada em consonância com as construções teóricas, mas, muitas vezes, foi necessário fazer novas leituras, a fim de compreender e discutir os aspectos emergentes, especialmente no caso das entrevistas. Para realizarmos a interpretação das entrevistas narrativas, mantendo o diálogo com os autores que fundamentam esse estudo, precisamos olhar para o texto e fazer um exercício intelectual que consistia em pensar: o que esse conteúdo nos diz? Assim, desenvolvemos guiões de auxílio à interpretação dos dados analisados nas entrevistas narrativas e semiestruturadas, com o objetivo de construir um raciocínio lógico sincronizado com a teoria e que permitisse, ao mesmo tempo, desenvolver textualmente a compreensão dos sentidos do conteúdo interpretado. O guião de auxílio (quadro 1) à interpretação foi fundamental e trouxe uma mais-valia ao processo de compreensão do conteúdo das entrevistas narrativas. 


\section{GUIÃO DE AUXÍLIO À INTERPRETAÇÃO DOS DADOS ANALISADOS NAS ENTREVISTAS NARRATIVAS}

\begin{tabular}{|c|c|c|}
\hline TÓPICO & OBJETIVO / QUESTÕES & $\begin{array}{c}\text { CATEGORIAS } \\
\text { RELACIONADAS } \\
\text { (NVIVo) }\end{array}$ \\
\hline $\begin{array}{l}\text { 1. Conhecendo a } \\
\text { Lúcia/Maria }\end{array}$ & $\begin{array}{l}\text { Objetivo: dar a conhecer o local de fala da } \\
\text { pessoa entrevistada. } \\
1 \text { - Quem é? } \\
2 \text { - O que fez em sua formação profissional? } \\
3 \text { - Quais as aspirações futuras? } \\
4 \text { - Quais suas qualidades? }\end{array}$ & A - Local de Fala \\
\hline \multirow{3}{*}{$\begin{array}{l}\text { 2. O ser estudante } \\
\text { extensionista do PAIE: } \\
\text { potencializando saberes } \\
\text { e construindo a relação } \\
\text { homem-mundo }\end{array}$} & $\begin{array}{l}\text { Objetivo: dar a conhecer e compreender } \\
\text { como se iniciou e se desenvolveu a } \\
\text { participação como extensionista no PAIE. } \\
1 \text { - O que motivou a participação no PAIE? } \\
2 \text { - Como foi o desenvolvimento curricular } \\
\text { da estudante durante as atividades? } \\
3 \text { - Como foi a interação com a } \\
\text { comunidade? } \\
4 \text { - Como a participação no PAIE } \\
\text { relaciona-se com o currículo do curso da } \\
\text { estudante? }\end{array}$ & $\begin{array}{l}\text { F - Justificativa } \\
\mathrm{C} \quad-\quad \text { Desenvolvimento } \\
\text { curricular da extensão } \\
\mathrm{D}-\text { Interação com a } \\
\text { comunidade }\end{array}$ \\
\hline & $\begin{array}{l}\text { Objetivo: dar a conhecer o modo com a } \\
\text { estudante extensionista Maria/Lucia vê o } \\
\text { mundo e como nele se insere. } \\
1 \text { - Como ela percebeu as realidades com } \\
\text { que se deparou ao participar do PAIE? } \\
2 \text { - Como ela agiu como participante do } \\
\text { PAIE na comunidade? } \\
3 \text { - Qual foi sua leitura de mundo como } \\
\text { participante do PAIE? }\end{array}$ & $\begin{array}{l}\text { B - Formação humana } \\
\text { integral }\end{array}$ \\
\hline & $\begin{array}{l}\text { Objetivo: dar a conhecer como foi a } \\
\text { imersão na sociedade e quais valores } \\
\text { relacionados à educação para a cidadania } \\
\text { foram desenvolvidos. } \\
1 \text { - Quais valores podem ser revelados a } \\
\text { partir da participação no PAIE? } \\
2 \text { - Como ela percebe os contributos do } \\
\text { PAIE à educação para a cidadania? } \\
3 \text { - Quais aprendizados ela mostra ter } \\
\text { desenvolvido? }\end{array}$ & $\begin{array}{l}\text { E - Inserção na comunidade } \\
\text { G - Desenvolvimento de } \\
\text { valores } \\
\text { H - Aspectos emergentes }\end{array}$ \\
\hline
\end{tabular}

NOTA:

- Aspectos emergentes compreendem: dificuldades, características dos participantes, relação com colegas de projeto, momentos marcantes e motivação dos participantes.

- Essa tabela foi elaborada a partir dos dados analisados durante a categorização no software NVivo.

Segundo Stake (2012), um estudo de caso exige disciplina e rigor nas explicações e, por isso, são necessários protocolos que não dependam da intuição ou de boas intenções. Nesse sentido, o autor afirma que na pesquisa qualitativa esses protocolos são chamados de 
triangulação e permitem-nos fazer inferências e reflexões que contribuem com a validade dos dados. Nesse sentido, após a análise e interpretação de todos os dados recolhidos/produzidos, procedemos à triangulação de fontes de dados com o objetivo defendido por Stake (2012). Essa foi a última etapa do processo de desenvolvimento da investigação e revestiu-se de elevada importância, uma vez que a triangulação de fontes de dados com entrevistas narrativas contribuiu para responder à questão principal e aos objetivos específicos da tese de doutoramento.

\section{Vozes das estudantes extensionistas: valores, atitudes e comportamentos desenvolvidos}

Lúcia é o codinome atribuído a uma participante de um projeto de extensão na área de Mecânica e Maria é o codinome atribuído a uma outra participante de um projeto de extensão na área de Informática que integraram o Programa de Apoio Institucional à Extensão no ano de 2017 no IFRN (Campus Mossoró). Para ouvir e compreender as vozes de Lúcia e Maria nos ancoramos em categorias analíticas que, agrupadas em função dos sentidos expressos pelas entrevistadas, resultaram na compreensão dos aspectos relacionados à educação para a cidadania que foram desenvolvidos durante a participação como estudante extensionista do Programa de Apoio Institucional à Extensão (PAIE).

A voz de Lúcia

Durante as etapas de planeamento e execução, o relato de Lúcia revela-nos o desenvolvimento de alguns valores, atitudes e comportamentos relacionados à educação para a cidadania, como: capacidade de trabalhar em equipe; autonomia; iniciativa/proatividade; persistência; responsabilidade.

A capacidade de trabalhar em equipe foi um valor muito presente durante as observações e que a voz de Lúcia, na entrevista, veio reforçar. Ela relata que no início do projeto, o grupo de seis extensionistas era solto e que se dividiram em duas equipas. O objetivo da divisão era que, durante a realização das atividades nas escolas, cada equipa trabalhasse com uma turma de participantes externos e depois se revezassem entre as turmas. A partir de então, passaram a organizar-se entre eles para que percebessem o que era necessário à implementação de cada experimento. A divisão de tarefas entre as duas equipas tornou mais fácil o que eles deveriam fazer e, ao mesmo tempo, fez com que o planemaneto corresse melhor. O trabalho em equipa consolidou-se ao longo do planeamento, pois ela relata que: "sempre antes das apresentações a gente vinha para dar uma olhada nos equipamentos, revisar mais uma vez quem 
era que ia falar o que [pausa] dos experimentos e explicar". Lúcia reconhece expressamente que a experiência como estudante extensionista foi uma mais-valia à capacidade de trabalhar em equipa:

É... Eu acho que, no geral, quando a gente se reuniu no CNC eu acho que foi, tipo, uma experiência a mais de trabalhar em grupo porque é uma coisa que a gente não estava ali obrigado, a gente escolheu fazer aquilo então, a gente não podia fazer tipo de qualquer jeito. Não é como se eu fosse obrigada a fazer esse projeto. Aí, então, pelo fato de a gente está ali, tínhamos que aprender a conviver com certas coisas. Esse grupo não era o grupo que anda junto na escola e tal. Foram pessoas aleatórias da sala, tipo eu não falava muito com Kleber, Antônia e tal. Então, foi juntando a gente e como não eram pessoas que a gente falava, a gente não sabia como, sei lá, fazer trabalhos em grupo com eles e a gente foi aprendendo a fazer isso. Algumas pessoas mais chatas, não vou dizer quem porque não está nem aqui nas fotos. Está aqui. Não tem nem como apontar porque nem aparecia, mas enfim. (LUCIA).

Como podemos perceber, ela reforça o caráter voluntário de participar num projeto de extensão e, como não estava por obrigação, era necessário aprender a conviver com os demais colegas para que o projeto caminhasse bem. Reforça ainda que os integrantes do grupo não eram do seu círculo de amizade e que não tinha muito contato com eles. Em função disso, ela relembra que não sabia como, inicialmente, fazer trabalhos em equipa com eles, mas que ao longo do tempo foi aprendendo, mesmo convivendo com pessoas "chatas". A experiência de Lúcia como extensionista aponta para o desenvolvimento de um sentido coletivo, construído em função de uma atividade educativa pensada para a comunidade do entorno do IFRN (Campus Mossoró). Precisamente neste aspecto que interpretamos, podemos afirmar que a dimensão extensão como uma hipótese de integralização ao currículo formal do estudante do Ensino Médio Integrado, sem ser uma componente obrigatória, configura-se como um processo de subjetivação desenvolvido pelo próprio educando (Pacheco, 2011). Por outras palavras, a extensão como escolha da estudante para integralizar a carga horária da prática profissional possibilitou que ela participasse no seu próprio processo formativo e desenvolvesse aprendizagens significativas que contribuem com o seu processo de humanização (Rogers, 2009), conforme reiterado pela estudante ao afirmar que foi aprendendo a "fazer trabalhos em grupo".

A autonomia desenvolveu-se durante o projeto à medida que ela se deparou com circunstâncias em que era preciso tomar decisões ou fazer escolhas para dar andamento às atividades. Para montar os experimentos, ela ressalta que foi aprendendo a fazer substituições e adaptá-los para a realidade dela, sem recurso financeiro para aquisição de itens específicos. O resultado da capacidade de decidir fazer modificações foi que os experimentos começaram a 
dar certo. A capacidade de iniciativa/proatividade está relacionada às tomadas de decisões feitas pela estudante durante o projeto. Nesse sentido, podemos apontar as seguintes atitudes: reuniões nos laboratórios por conta própria, procura de itens para os experimentos; opção pelos experimentos mais simples em função dos materiais que tinham, decisão sobre troca, compra e quais materiais poderiam ser usados.

No que concerne ao desenvolvimento da capacidade de autonomia $\mathrm{e}$ iniciativa/proatividade, percebemos com base em Kamii (2002), que diante de algumas circunstâncias ela considerou os factos relevantes e decidiu por si mesma a melhor maneira de agir para resolver os problemas que atingiam toda a equipa. Isso demonstra que essa experiência vivida, conforme argumenta Bruner (1999), pode ser projetada em outras situações futuras, uma vez que o processo formativo pode estruturar o seu comportamento na sociedade.

A persistência da estudante pode ser percebida ao Lúcia relatar que tentava várias vezes realizar um experimento quando ele não corria bem e que, quando estava sozinha (sem o acompanhamento dos coordenadores), "pulava para o outro experimento e ia tentar outra vez". O estímulo à responsabilidade foi descrito por Lúcia ao referir-se à necessidade de fazer aquilo que era delegado pelos coordenadores do projeto e de arranjar os experimentos para que eles funcionassem durante as atividades na comunidade. Acerca da persistência e responsabilidade, podemos perceber à luz do pensamento de Carvalho e Síveres (2013) que a estudante demonstrou motivação, envolvimento e esforço no processo de aprendizagem, pois mesmo enfrentando dificuldades ela manteve-se persistente para realizar as atividades e cumprir com as responsabilidades que assumiu.

De entre os aspectos emergentes que pudemos perceber na análise da narrativa, Lúcia relata algumas dificuldades na etapa de planeamento das atividades. A principal dificuldade apontada foi o facto de o Programa de Apoio Institucional à Extensão (PAIE) não ter disponibilizado o recurso previsto para aquisição de materiais que eram fundamentais à execução do projeto, como um dinamômetro, por exemplo. Com isso, ela relata que foram dadas sugestões de adaptações nos experimentos, mas ainda foi necessária a aquisição de alguns materiais pelos coordenadores. O desenvolvimento dos experimentos contou ainda com problemas no trabalho de equipa, erros no funcionamento dos experimentos, sensação de que não sabia como fazer os experimentos e dificuldade em atender às solicitações dos coordenadores. Contudo, estas dificuldades foram superadas gradualmente ao longo do processo e parecem ter servido de um momento de aprendizagem que pode ter impulsionado o desenvolvimento de algumas atitudes e comportamentos que foram analisamos e interpretamos anteriormente a partir da voz de Lúcia. 
Nesse aspecto das dificuldades e superações durante o desenvolvimento de atividades de extensão por meio da metodologia de projetos, podemos perceber, amparados em Barbosa, Gontijo e Santos (2004), que os professores coordenadores assumiram um papel de facilitadores e orientadores do processo de aprendizagem, por meio de uma relação horizontalizada com os estudantes num contexto marcado, essencialmente, pela necessidade de elaboração de estratégias e resolução de problemas que surgiram no decorrer da implementação do projeto.

A voz de Maria

A interação de Maria com a comunidade revela-nos o desenvolvimento de alguns valores, atitudes e comportamentos relacionados com a educação para a cidadania, como: solidariedade; tolerância; atenção a problemas específicos dos participantes; respeito ao próximo; autonomia; uso de estratégias para estimular a participação dos alunos externos.

A solidariedade pode ser percebida na narrativa de Maria quando ela relata que durante uma aula um participante recebeu a notícia de que o pai dele tinha morrido. Diante deste facto, ela deu-lhe os pêsames e não ligou para que ele voltasse a assistir às aulas, pois compreendeu o momento pelo qual a família estava a passar. O PAIE parece assumir um carácter imprescindível na formação de Maria, uma vez que o contexto narrado foi singular e provocou nela uma reação solidária que pode ser entendida como a capacidade de compreender e sensibilizar-se com o outro diante de determinadas circunstâncias (Delors et al., 1998).

Maria relata que uma das principais aprendizagens que teve, ao conviver com os participantes da comunidade externa, foi a paciência que aprendeu a reforçar, pois os alunos eram muito jovens e cheios de euforia. Acerca desse processo ela descreve que:

Uma era uma turma de adultos é que eu precisava é... estimulá-los a estudar e a outra turma era uma turma de jovens que tinha muita, muita sagacidade para estudar e eu precisava é... equilibrar essa sagacidade deles que eles tinham demais (MARIA).

Uma coisa que eu aprendi, pronto um aprendizado para, dessa turma, foi a paciência. Eu tive muita paciência é... eu já tinha adquirido experiência, é paciência com as experiências passadas né. De lecionar. Mas essa turma que eu me... eu fiz doutorado em paciência [risos], que eles eram, não por teimosia, mas, eles conversavam muito. (MARIA).

Maria refere que em ambas as turmas foi preciso ser tolerante, pois eram muito heterogêneas. Com base em Machado (2006), podemos perceber que a tolerância de Maria esteve fundada na sua capacidade de compreender o perfil dos participantes externos que compunham as diferentes turmas e reconhecê-los como seres com diferentes peculiaridades. Numa turma Maria precisava estimulá-los a estudar e na outra a equilibrar a energia que eles 
tinham ao conversarem entre si. Com efeito, ela reconhece que, embora já tivesse tido experiências anteriores lecionando, foi preciso ter muita paciência para aprender a lidar com o comportamento deles. Assim, em diálogo com Machado (2006), inferimos que Maria desenvolveu a capacidade de colocar-se no lugar dos participantes, enriquecendo a sua própria perspectiva (paciência) a partir das diferenças que eles demonstravam ter. Com isso, a tolerância foi o valor que Maria mais ressaltou ter desenvolvido ao longo das atividades.

A capacidade de ter atenção a problemas específicos dos participantes esteve relacionada com a preocupação de Maria em relação à ausência de alguns participantes nas aulas e ao relato de um aluno sobre a relação com o pai. Na primeira situação, quando ela percebeu que muitos estavam a faltar, fez ligações para saber o que estava a acontecer ou foi até a casa deles para conversar pessoalmente. A segunda circunstância aconteceu quando um participante, durante uma dinâmica de grupo, escreveu em um papel que seu pai não lhe dava atenção, deixando Maria chateada, pois ela não entendia como aquilo era possível, visto que o aluno era uma pessoa simpática. As situações relatadas permitem-nos perceber, a partir de Delors et al. (2010), que Maria sinaliza o desenvolvimento da capacidade de aprender a prestar atenção a factos (ausência de participantes) e às pessoas (participante com dificuldade de relacionar-se com o pai). Para Delors et al. (1998), a "aprendizagem da atenção pode revestir formas diversas e tirar partido de várias ocasiões da vida [...]" (p. 92), reforçando assim, a relevância do PAIE na formação de Maria.

O respeito ao próximo está relacionado com a capacidade de ser tolerante e pode ser percebido no discurso de Maria quando ela relata que foi visitar alguns alunos faltosos da primeira turma, a fim de saber por que eles não estavam a frequentar as atividades. Diante das explicações que eles deram, Maria relata que compreendeu os seus argumentos e mostrou-se sensível aos problemas alheios ao entender que eles tinham outras preocupações para além de um curso de informática. Para Martins (2009), é por meio do "respeito aos outros que o indivíduo se abre a outras possibilidades (aprendizagem, de valores) para enfrentar os conflitos e os problemas da vida e, simultaneamente, ter a oportunidade de crescer como pessoa" (p. 18). Na perspectiva apontada por Delors et al. (1998), podemos perceber que o respeito de Maria pelos problemas relatados pelos participantes ausentes, evidencia o desenvolvimento da sua capacidade de aprender a ser, sob a mediação do PAIE.

Martins (2009) defende que educar para a cidadania significa também formar para a autonomia do educando. Nesse sentido, a autonomia de Maria pode ser perceptível quando ela apontou que tinha que ir dar aulas às sextas-feiras para terminar atividades com uma turma mais cedo e quando marcou o período de inscrição dos participantes ao fazer divulgação nas escolas. 
Assim, diante de algumas circunstâncias, ela teve a necessidade de tomar decisões que entendeu serem necessárias para que o prosseguimento das atividades seguisse normalmente. A autonomia individual (Martins, 2009) foi um outro aspecto que parece ter sido desenvolvido em função da participação de Maria no PAIE.

O uso de estratégias para estimular a participação dos alunos externos está relacionado à capacidade de aprender a fazer, um dos quatro pilares educacionais defendidos por Delors et al. (1998). Isso significa que, no contexto do PAIE, Maria precisava colocar em prática os seus conhecimentos técnicos e adaptá-los à compreensão dos participantes do projeto. Assim, ela parece ter usado diferentes meios didáticos que corroboraram para a consolidação de uma interação dialógica entre ela e os participantes. Nesse sentido, podemos observar que o discurso de Maria remete para a realização de dinâmicas de grupo e de seminários com os participantes do projeto. Assim, os participantes tiveram a hipótese de se envolver e aprender os conteúdos de informática, por meio de diferentes estratégias pensadas por Maria. Os diferentes métodos para levar os participantes a interagir durante as aulas são fruto da capacidade de aprender a aprender (Delors et al., 1998), estimulada e desenvolvida durante as experiências sociais que o PAIE proporcionou à extensionista.

Os valores, atitudes e comportamentos relacionados à educação para a cidadania que pudemos perceber no discurso de Maria foram desenvolvidos durante a interação com os participantes da comunidade externa. Neste contexto, à luz do pensamento de Cortina (2005), Nussbaum (2012), Delors et al. (1998) e Martins (2009) podemos afirmar que estes valores são componentes inevitáveis da vida humana e que são próprios de uma sociedade que almeja desenvolver as capacidades humanas relacionadas à educação para a cidadania. Portanto, podemos afirmar que o Programa de Apoio Institucional à Extensão (PAIE) parece contribuir, fundamentalmente, para cultivar, nos estudantes do Ensino Médio Integrado, valores relacionados ao ato de educar para a cidadania.

\section{Considerações finais}

Os sentidos evidenciados durante a análise de conteúdo das entrevistas narrativas apontaram uma convergência nas vozes de Lucia e Maria que é a potencialização do ser humano mediada pela relação com a comunidade externa. Ambas as estudantes desenvolveram atividades em diferentes projetos, mas tiveram um elo comum que foi a conexão com a sociedade, pois elas precisaram sair dos muros escolares para desenvolver, in loco atividades que dialogavam com participantes externos por meio das suas diferentes áreas de formação 
técnica (Mecânica e Informática). Diante desta zona de convergência, podemos perceber que as estudantes desempenharam um duplo papel como agentes de transformação social, pois à medida que agiam, transformavam o mundo ao redor e, ao mesmo tempo, transformavam-se.

As atividades realizadas pelas estudantes extensionistas proporcionaram vivências peculiares em comunidades e resultaram em um processo de aprendizagem propício ao desenvolvimento da formação humana integral, uma vez que as envolveu em diferentes realidades sociais, permitindo a análise, reflexão, produção coletiva de conhecimentos e descoberta de objetos de aprendizagem (Araújo, Rodrigues \& Silva, 2014).

Assim, as atividades de extensão perpassaram o acesso ao conhecimento técnico, tendo possibilitado às estudantes a compreensão dos problemas sociais e produção de novos conhecimentos em função de interesses sociais coletivos (Moura \& Pinheiro, 2009). A articulação entre a escola e a sociedade, possibilitou ainda que as extensionistas pudessem agir sobre a realidade, tendo como ponto de partida a difusão do conhecimento técnico para dinamizar os problemas sociais. Nesse sentido, podemos afirmar que a participação no Programa de Apoio Institucional à Extensão (PAIE) corroborou com a perspectiva dos três sentidos da integração curricular defendidos por Ramos (2008): formação omnilateral, indissociabilidade entre educação profissional e educação básica e a integração de conhecimentos gerais e específicos como totalidade. A formação omnilateral foca-se no desenvolvimento humano e não apenas no mercado de trabalho (Ramos, 2008). A indissociabilidade entre educação profissional e educação básica relaciona-se com a necessidade de possibilitar ao estudante a compreensão do contexto para que ele possa agir em função dos interesses coletivos (Moura, 2007). A integração de conhecimentos gerais $e$ específicos como totalidade pode ser compreendida como a vinculação de conhecimentos contextualizados à realidade concreta dos alunos (Ramos, 2008; Moura, 2007).

Esses dois perfis tão distintos dividem o ambiente escolar do IFRN e se conectaram entre si mediante um elemento comum: o desenvolvimento de projetos de extensão por meio do PAIE. As experiências foram completamente diferentes em função da natureza e dos objetivos dos projetos, mas as duas participaram da comunidade, interferindo na construção de uma realidade e vivenciando processos semelhantes de formação humana que parecem estar além da instrumentalização para o trabalho em suas áreas técnicas.

As entrevistas narrativas permitiram compreender aspectos advindos de diferentes histórias que expressaram momentos de formação vividos em contextos específicos integrados por meio de processos metodológicos. Reconhecemos na utilização do software de análise uma mais valia não apenas técnica, mas sobretudo pela possibilidade que nos dá para explicitar 
processos de subjetividade na análise e na interpretação consequente. Além disso, os processos tornam-se mais claros e replicáveis por quem ler a investigação disseminada, permitindo, simultaneamente, que leituras por outros olhares leve a outras interpretações e a conclusões igualmente válidas. Em artigos científicos, como é o caso, esse aspecto é especialmente relevante, porque se atenuam as influências de recortes sem perdermos a percepção da globalidade do processo de investigação.

Assim, a produção das narrativas e as opções de análise podem se constituir em propostas e avanços teórico-metodológicos que o rigor científico e interpretação em profundidade podem alcançar para possibilitar a reflexão dos sujeitos sobre si e o mundo que os cercam.

\section{REFERÊNCIAS}

AFONSO, N. Investigação naturalista em educação: um guia prático e crítico. Vila Nova de Gaia: Fundação Manoel Leão, 2014.

ARAÚJO, R. M. de L., RODRIGUES, D. do S., \& SILVA, G. P. da. Ensino integrado como projeto político de transformação social. Trabalho \& Educação, v. 23, nº 1, p. 161-186, 2014. Consultado em fev. 2017. Disponível em https://periodicos.ufmg.br/index.php/trabedu/article/view/9302.

BOGDAN, R., \& BIKLEN, S. K. Investigação qualitativa em educação. Porto: Porto Editora, 1994.

BRUNER, J. The Process of Education. Cambridge: Harvard University Press, 1999.

BARBOSA, E. F., GONTIJO, A. D. F., \& SANTOS, F. F. dos. O Método de Projetos na Educação Profissional: ampliando as possibilidades na formação de competências. Educação Em Revista, $n^{\circ}$ 40, p. 187-212, 2004. Consultado em fev. 2019. Disponível em http://www.tecnologiadeprojetos.com.br/banco_objetos/\%7B9D658D0F-F54C-4741A0E6-F85921673FF0\%7D_metodo\%20de\%20projeto.pdf.

CARVALHO, F. G. B., \& SÍVERES, L. A dinâmica motivacional no processo de aprendizagem na extensão universitária. In L. Síveres (Ed.), A extensão universitária como um princípio de aprendizagem, p. 37-58. Liber Livro, 2013.

COSTA, L. da. \& NUNES, S. Tornar-se educadora/professora - palavras que contam como foi! Revista da FAEEBA - Educação e Contemporaneidade, v. 25, no 47, p. 119-136, 2016.

CORTINA, A. Cidadãos do mundo: para uma teoria da cidadania. São Paulo: Edições Loyola, 2005.

DAY, C. Desenvolvimento profissional de professores. Os desafios da aprendizagem 
permanente. Porto: Porto Editora, 2001.

DELORS, J., Al-MUFTI, I., AMAGI, I., CARNEIRO, R., CHUNG, F., GEREMEK, B., GORHAM, W., KORNHAUSER, A., MANLEY, M., QUERO, M. P., SAVANÉ, M., SINGH, K., STAVENHAGEN, R., SUHR, M.W., NANZHAO, Z. Educação: Um Tesouro a Descobrir. Brasília: Unesco, 2010.

DELORS, J., AL-MUFTI, I., AMAGI, I., CARNEIRO, R., CHUNG, F., GEREMEK, B., GORHAM, W., KORNHAUSER, A., MANLEY, M., QUERO, M. P., SAVANÉ, M., SINGH, K., STAVENHAGEN, R., SUHR, M.W., NANZHAO, Z. Educação: um tesouro a descobrir. Relatório para a UNESCO da Comissão Internacional sobre Educação para o Séc. XXI. Unesco da Comissão Internacional sobre Educação. São Paulo: Cortez, 1998.

DENZIN, N. \& LINCOLN, Y. S. The Sage handbook of qualitative research. 3. ed. London: Sage Publications, 2005.

DELORY-MOMBERGER, C. Abordagens metodológicas na pesquisa biográfica. Revista Brasileira de Educação, v. 17, nº 51, p. 523-536, 2012.

DUBAR, C. A socialização: construção das identidades sociais e profissionais. Brasil: Livraria Martins Fontes Editora Ltda, 2005.

FERRAROTTI, F. Sobre a ciência da incerteza. O método biográfico na investigação em ciências sociais. Mangualde: Edições Pedago, 2013.

FLICK, U. Métodos qualitativos na investigação científica. Lisboa: Monitor, 2005.

FONTANA, A., \& FREY, J. The interview: from neutral stance to political involvement. In N. Denzin \& Y. Lincoln (Eds.), Handbook of qualitative research, p. 695-727. Thousand Oaks; London; New Delhi: Sage Publications, 2005.

GOODSON, I. F. Conhecimento e vida profissional. Estudos sobre educação e mudança. Porto: Porto Editora, 2008.

GRAY, D. Pesquisa no mundo real. 2a ed. Porto Alegre: Penso, 2012.

JOSSO, M. C. A transformação de si a partir da narração de histórias de vida. Educação, v. 3, no 63 , p. 413-438, 2007.

JOVCHELOVITCH, S., \& BAUER, M. W. Entrevista narrativa. In M. W. Bauer \& G. Gaskell (Eds.) Pesquisa qualitativa com texto: imagem e som: um manual pratico, p. 90-113). Petrópolis-RJ: Vozes, 2002.

KAMII, C. A autonomia como finalidade da educação: implicações da Teoria de Piaget. In A criança e o número. 29. ed., p. 103-124. Campinas: Papirus, 2002.

MACHADO, N. J. Educação: projetos e valores. 6. ed. São Paulo: Escrituras Editora, 2006. 
MARTINS, E. C. A escola como espaço gerador de cultura "de" e "para" a cidadania. Plures Humanidades, $n^{\circ}$ 12, p. 12-31, 2009. Consultado em mar. 2018. Disponível em https://repositorio.ipcb.pt/bitstream/10400.11/834/1/EM_Plures 12.pdf.

MOURA, D. H., \& PINHEIRO, R. A. Currículo e formação humana no ensino médio técnico integrado de jovens e adultos. Em Aberto, v. 22, no 82, p. 91-108, 2009. Consultado em fev. 2017. Disponível em http://rbep.inep.gov.br/ojs3/index.php/emaberto/article/view/2450.

MOURA, D. H. Educação Básica e Educação Profissional e Tecnológica: Dualidade Histórica e Perspectivas de Integração. Holos, v. 2, nº 23, p. 4-30, 2007. Consultado em fev. 2017. Disponível em http://www2.ifrn.edu.br/ojs/index.php/HOLOS/article/viewFile/11/110.

MUYLAERT, C. J., SARUBBI, V. J., GALLO, P. R., LEITE, M., \& NETO, R. Entrevistas narrativas: um importante recurso em pesquisa qualitativa. Revista da Escola de Enfermagem da USP, v. 48, $n^{\circ}$ Esp 2, p. 193-199, 2014. https://doi.org/10.1590/S0080-623420140000800027

NUSSBAUM, M. C. Crear capacidades. Barcelona: Book Print, 2012.

PASSEGGI, M. C. A experiência em formação. Educação, v. 34, nº 2, p. 147-156, 2011.

PACHECO, E. Institutos Federais uma Revolução na Educação Profissional e Tecnológica. Brasília; São Paulo: Fundação Santillana; Editora Moderna, 2011.

PINEAU, G. As histórias de vida em formação: gênese de uma corrente de pesquisaação-formação existencial. Educação e Pesquisa, v. 32, no 2, p. 329-343, 2006.

RAMOS, M. Concepção do ensino médio integrado. In Seminário sobre Ensino Médio, p. 1-30, 2008. Rio Grande do Norte: Secretaria de Educação do Estado do Rio Grande do Norte. Consultado em mar. 2017. Disponível em https://tecnicadmiwj.files.wordpress.com/2008/09/texto-concepcao-do-ensino-mediointegrado-marise-ramos1.pdf

ROGERS, C. Tornar-se pessoa. 6. ed. São Paulo: Martins Fontes, 2009.

STAKE, R. A arte de investigação com estudos de caso. 3. ed. Lisboa: Fundação Calouste Gulbenkian, 2012.

SZYMANSKI, H., ALMEIDA, L. R. de, \& PRANDINI, R. C. A. R. A entrevista na educação: a prática reflexiva. Brasília: Liber Livro, 2011.

SARMENTO, T. Formação de professores para uma sociedade humanizada. Revista de Educação PUC-Campinas, v. 22, nº 2, p. 285-297, 2017.

SARMENTO, T. Histórias de vida de educadoras de infância. Lisboa: Instituto de Inovação Educacional, 2002. 
UBAQUE, D. F. \& CASTAÑEDA-PEÑA, H. Teacher research: uncovering professional identities and trajectories of teacher researchers through narrative research-a colombian case. International Education Studies-Canadian Center of Science and Education, v. $10, \mathrm{n}^{\mathrm{o}} 3$, p. 35-45, 2017.

VIEIRA, R. Identidades, histórias de vida e culturas escolares: contribuições e desafios para a formação de professores. In Seminário de Educação "Memórias, histórias e formação de professores", 3., 2007, Rio de Janeiro. Anais... Rio de Janeiro: 2007. p. 1$17,2007$.

VILELAS, J. Investigação: o processo de construção do conhecimento. 2. ed. Lisboa: Edições Sílabo, 2017.

YIN, R. Estudo de caso: planejamento e métodos. 5. ed. Porto Alegre: Bookman, 2015.

YIN, R. Pesquisa qualitativa do início ao fim. Porto Alegre: Penso, 2016.

\section{SOBRE OS AUTORES:}

\section{Conceição Leal da Costa}

Doutora em Ciências da Educação. Docente do Departamento de Pedagogia e Educação da Escola de Ciências Sociais da Universidade de Évora (UE). Investigadora do Centro de Investigação e Educação e Psicologia (CIEP|UE) - Portugal. E-mail: mclc@uevora.pt

(iD https://orcid.org/0000-0003-3299-6845

\section{João Paulo Oliveira}

Doutor em Ciências da Educação. Instituto Federal de Rio Grande do Norte (Brasil). Investigador do Centro de Investigação e Educação e Psicologia (CIEP|UE) - Portugal. E-mail: jprussasce@gmail.com

(iD https://orcid.org/0000-0002-6582-8402

\section{Isabel Cavas}

Doutoranda em Ciências da Educação pela Universidade de Évora (UE). Colaboradora do Centro de Investigação e Educação e Psicologia (CIEP|UE) - Portugal. Bolsista da Fundação para a Ciência e a Tecnologia (FCT). E-mail: isabelcavas@gmail.com

(iD) https://orcid.org/0000-0003-2142-5406 